\title{
POTENCIAL TURÍSTICO DA GEODIVERSIDADE DO MUNICÍPIO DO UIRAMUTÃ - RORAIMA
}

Márcia Teixeira Falcão

Professora Doutora do Curso de Geografia

Universidade Estadual de Roraima - UERR

marciafalcao.geog@uerr.edu.br

Jardene Ângelo de Souza

Acadêmica do Curso de Turismo

Universidade Estadual de Roraima - UERR

jardenesouza19@gmail.com

\section{Randielly Barbosa Soares}

Licenciada em Geografia

Universidade Estadual do Amazônas - UEA

rbodoratasoares@gmail.com

\author{
Bruno Dantas Muniz de Brito \\ Professor do Curso de Turismo \\ Universidade Estadual de Roraima - UERR \\ Doutorando em Geografia \\ Universidade Federal do Ceará - UFCE \\ brunodibrito@hotmail.com
}

\section{RESUMO}

0 artigo teve como objetivo demonstrar o potencial turístico da geodiversidade do município do Uiramutã - Roraima, visando contribuir como alternativa para o desenvolvimento econômico da região. As autorizações para a realização da investigação se deu mediante as prefeitura do município, trâmites éticos e povo ingarikó. A metodologia envolveu estudos bibliográficos, observações in loco, sobrevoo e aplicação de metodologia de checklist para avaliar o potencial da geodiversidade local. 0 resultados demonstram que a região estudada possui grande geodiversidade que infere potencial para o desenvolvimento do turismo como alternativa econômica para região e os povos que ali vivem possuem conhecimento sobre a geodiversidade incluindo trilhas demarcadas, tipo de atividade ecoturística, além da cultura através dos mitos e ritos sobre a região. Ressalta-se ainda que o turismo em terra indígenas está regulamentado através da Instrução Normativa 03/2015, da FUNAI, a qual estabelece normas para a visitação para fins turísticos em terras indígenas.

Palavras - chave: Geodiversidade. Turismo. Terras Indígenas. Uiramutã-RR.

\section{RESUMEN}

El artículo tuvo como objetivo demostrar el potencial turístico de la geodiversidad del municipio de Uiramutã - Roraima, buscando contribuir como alternativa para el desarrollo económico de la región. Las autorizaciones para la realización de la investigación se dio mediante las municipalidades del municipio, trámites éticos y el pueblo ingarikó. La metodología involucró estudios bibliográficos, observaciones in situ, sobrevuelo y aplicación de metodología de checklist para evaluar el potencial de la geodiversidad local. Los resultados demuestran que la región estudiada posee gran geodiversidad que infiere potencial para el desarrollo del turismo como alternativa económica para la región y los pueblos que alli viven poseen conocimiento sobre la geodiversidad incluyendo senderos demarcados, tipo de actividad ecoturística, además de la cultura a través de los mitos y ritos sobre la región. Se resalta además que el turismo en tierras indígenas está regulado a través de la Instrucción Normativa 03/2015, de la FUNAl, la cual establece normas para la visitación para fines turísticos en tierras indígenas.

Palabras clave: Geodiversidad. Turismo. Tierras Indígenas. Uiramutã-RR. 


\section{INTRODUÇÃO}

O desenvolvimento da pesquisa se deu a partir da perspectiva do interesse geomorfológico, no qual o município estudado possui uma grande riqueza paisagística, resultado da dinâmica natural ao longo do tempo, condicionado pelas flutuações climáticas e esforços tectônicos.

O desenvolvimento da pesquisa ocorreu no município do Uiramutã, localizado na porção na porção nordeste do estado de Roraima e constitui em área de sobreposição do Parque Nacional (PARNA) do Monte Roraima com a Terra Indígena Raposa Serra do Sol, região de domínio da etnia Ingarikó, e com os países República Bolivariana da Venezuela e República Cooperativista da Guiana.

O município de Uiramutã possui uma grande variação de elementos significativos para a geodirvesidade, como os valores científicos, paisagísticos e turísticos, assim o estudo dessa área através do estudo geomorfológico pode gerar impactos positivos para a sua geoconservação e desenvolver a economia através do turismo nessas áreas.

O objetivo da pesquisa é demonstrar o potencial turístico da geodiversidade do município do Uiramutã - Roraima, visando contribuir como alternativa para o desenvolvimento econômico da região, através da identificação das áreas de interesses geomorfológicos; mapeamento as áreas de interesse geomorfológico no entorno da sede e a divulgaçãodo potencial do geopatrimônio da área de estudo.

\section{O TURISMO E A GEODIVERSIDADE}

O estado de Roraima apresenta um grande potencial turístico, sendo internacionalmente conhecido através do turismo realizado no Parque Nacional do Monte Roraima, no qual Silva, Cruz e Py-Daniel (2011) ressaltam ainda a vivencia e percepção de como são re- alizadas, operacionalizadas e administradas às atividadesturísticas em Parques Nacionais junto com etniasindígenas venezuelanaas, já Fernandes-Pinto e Irving (2015) comentam a presença de ambientes diversificados e comcaracterísticas geológicas e ecológicas únicas encontrados na região. O turismo é uma atividade econômica que faz uso e consumo da paisagem, e essa por sua vez, pode provocar deslocamento de grandes massas humanas.

Nesse sentido, o turismo utiliza a geodiversidade, termo recente que surgiu na década de 90 para se referir a variedade abiótica, ou seja dos ambientes geológicos-geomorfólogicos que dão forma a paisagem (NASClMENTO; RUCHKYS; MANTESSO-NETO, 2008).

Brilha (2005) dá destaque a geodiversidade através da atribuição de valores, classificados conforme o quadro 01 abaixo:

\begin{tabular}{|l|l|}
\hline \multicolumn{1}{|c|}{ VALOR } & \multicolumn{1}{c|}{ CARACTERÍSTICA } \\
\hline Intresíseco & $\begin{array}{l}\text { Trata da elação entre homem e na- } \\
\text { tureza, no qual o ser humano é parte } \\
\text { integrante da natureza }\end{array}$ \\
\hline Cultural & $\begin{array}{l}\text { Liga o serhumano e a sua cultura ao } \\
\text { meio fisico, tornando-os interdepen- } \\
\text { dentes, entre o desenvolvimento so- } \\
\text { cial, cultural e/ou religioso e o meio } \\
\text { fisico circundante. }\end{array}$ \\
\hline Estético & $\begin{array}{l}\text { Évisivel nas mais diversas paisagens, } \\
\text { no qual algumas pessoas ase conten- } \\
\text { tarem apenas com a observação da } \\
\text { geodiversidade por ser um atoinstin- } \\
\text { tivo, consensual e agradável. }\end{array}$ \\
\hline Econômico & $\begin{array}{l}\text { Satisfaz as necessidades do ser hu- } \\
\text { mano,pois são atribuídos valores aos } \\
\text { bens e serviços, pois a evolução da } \\
\text { sociedade esteve sempre dependen- } \\
\text { te da utilização deelementos da geo- } \\
\text { diversidade. }\end{array}$ \\
\hline Funcional & $\begin{array}{l}\text { Se através da utilização da geodiver- } \\
\text { sidade que pode ser in situ, ou como } \\
\text { sustentação dos sistema fisicos e } \\
\text { ecológicos }\end{array}$ \\
\hline
\end{tabular}




\begin{tabular}{|l|l|}
\hline Científico & $\begin{array}{l}\text { Auxilia nareconstrução da história da } \\
\text { Terra e auxilia nos estudos para me- } \\
\text { Ihorar a relação homem e geodiversi- } \\
\text { dade, contribuindo para minimizar os } \\
\text { impactos sobre o ambiente natural. }\end{array}$ \\
\hline Educativo & $\begin{array}{l}\text { Contribui para o uso da geodiversida- } \\
\text { decomo sala deaula ao ar livre, per- } \\
\text { mitindo o contato direto para a ob- } \\
\text { servação de exemplosconcretos seja } \\
\text { no âmbito escolar ou com o público } \\
\text { em geral, ou seja no sentido formal e } \\
\text { informal. }\end{array}$ \\
\hline
\end{tabular}

Quadro 01. Valores da Geodiversidade. Fonte: Organizado pelos autores através dos trabalhos de Brilha, 2005; Nascimento; Ruchkys; Mantesso-Neto, 2008 e Garcia, 2014.

A partir do quadro 01, percebe-se que a atividade turística se permite utilizar os valores da geodiversidade, agregando motivações para satisfazer as necessidades do turista em conhecer paisagens, cultura, educação e outros. Irving (2009, p. 109) comenta que há "uma mudança sutil no perfil deturistas, conectados progressivamente com os temas da responsabilidade social eambiental", e esse "novo turista' busca novas experiências, descobertas e oportunidade devivências e aprendizagens.

Com relação ao geoturismo, autores como Moreira (2010) comenta que o que diferencia o ecoturismo doturismo convencional, é ofato do primeiro ser considerado uma segmentação turística ambientalmente responsável, que cumprecritérios e princípios básicos de sustentabilidade e infere um caráter educativo trabalhando a percepção e a importância de conservar a natureza. E o geoturismo, termo que surgiu em 1995 com pesquisador inglês Thomas Hose, também segue os parâmetros do ecoturismo, mas tem como principal atrativo a geodiversidade.

\section{METODOLOGIA}

\section{ÁREA DE ESTUDO}

A pesquisa foi realizada no Uiramutã, o município que faz fronteira com dois países
(República Bolivariana da Venezuela e República Cooperativista da Guiana). Os estudos de campo ocorreram no entorno da sede do município e na comunidade indígena Ingarikó (Figura 01).

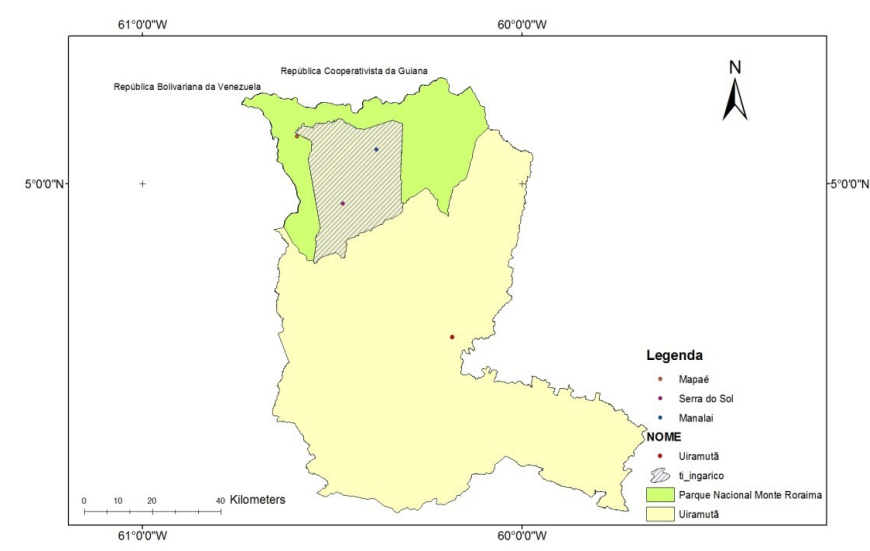

Figura 01. Mapa de localização do município do Uiramutã. Fonte: Autores, 2016.

\section{PROCEDIMENTOS}

Os procedimentos adotados, se deu a partir de levantamento bibliográfico, incursões em campo no período de 2014 e 2018, sobrevoos no qual foram realizadas coletas da localização de cada ponto de interesseatravés do Sistema de Posicionamento Global - GPS, foi aplicado método checklist baseado em Oliveira (2015) para avalições do potencial geomorfológico. 0 método se caracteriza por ser uma ficha descritiva, no qual contempla os seguintes aspectos: identificação (município, coordenadas geográficas, tipo de propriedade); potencial da geodiversidade (valores, acessibilidade), bem como os impactos ambientais presentes na área.

O desenvolvimento da pesquisa se deu através de sobrevoo e da visitação nas áreas com potencial para geodiversidade e a realização de diagnóstico das áreas de interesse turístico. No decorrer da pesquisa foram realizadas entrevistas com os interlocutores, no caso os indígenas da região ingarikó.

A entrevista foi mediante a assinatura do 
Termo de Consentimento Livre e Esclarecido (TCLE) e termo de autorização para o uso de imagem, segundo as normas estabelecidas pela Resolução no196, do Conselho Nacional de Saúde de 10/1996 e aprovado pelo Comitê de Ética em Pesquisa da Universidade Federal de Roraima (no 1.001.442), pelo Instituto do Patrimônio Histórico e Artístico Nacional (no 24/2014) e pela Fundação Nacional do índio - FUNAI (no 28/AAEP/PRES/2025) o qual o indivíduo teve liberdade de aceitar ou não em participar da pesquisa.

As assinaturas dos termos foram obtidas individualmente, após serem explicados verbalmente os objetivos e a metodologia que seria utilizada na pesquisa. Após as entrevistas in loco, os dados foram tabulados e analisados através de tabelas e gráficos.

O material cartográfico e os dados geológicos-geomorfológicos foram embasados nos mapas do Instituto Brasileiro de Geografia e Estatística - IBGE (1983) NB-20-Z-B e NB-20-Z-D, escala 1:250.000. Os mapas foram produzidos na escala 1:100.000, tendo como base os shapes disponibilizados pelo Instituto Brasileiro de Geografia e Estatística - IBGE (2013).

\section{RESULTADOS E DISCUSSÃO}

\section{ÁREAS DE INTERESSES E COM PO- TENCIAL GEOMORFOLÓGICO}

A fisiografia da área se caracteriza pela vegetação é influenciada pelo tipo climático (Aw), caracterizada ao norte do municipio pelapresença da floresta ombrófila, e campos rupestres e na porção centro-sul do município predominam as savanas.

A geologia pertence ao chamado Supergrupo Roraima (1,78 Ga), Reis e Costi (1990) em seus estudos relacionaram o desenvolvimento geológicodessa região a um evento distensional com direção geral N-S, responsável pelodesenvolvimento de falhas normais E-W e de transferência.
A geomorfologia da região é marcada pelo Planalto Sedimentar de Roraima constitui uma unidade morfoestrutural com presença de relevos tabulares esculpidos em rochas sedimentares e metassedimentares do então Supergrupo Roraima, e o relevo se configura por ser acidentado, marcado por vertentes íngremes recobertas por depósitos de encosta.

$\mathrm{Na}$ região, destacam-se a presença de grandes mesas (chamada regionalmente pelos indios de tepuys), com topos em geral aplainados que se destacam de forma isolada, a exemplo do Monte Roraima, que possui uma pequena área no território brasileiro, apenas 5\% (Figura 02).
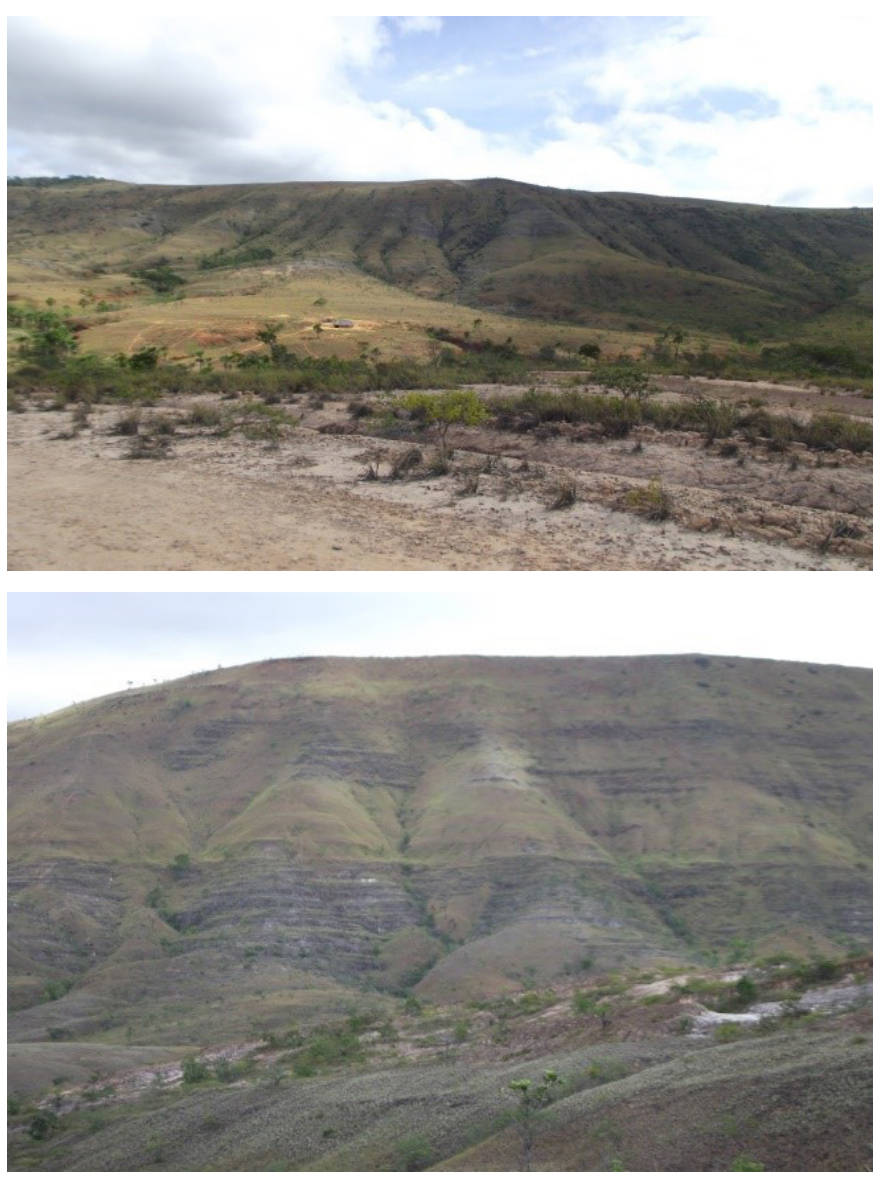

Figura 02. Geomorfologia do município do Uiramutã, esculpida em rochas sedimentares e metassedimentres. Fonte: Acervo fotográfico de Falcão, 2016.

A área de estudo é representada pela área indígena denominada Raposa Serra do Sol (TIRSS), habitada pelos índios da etnia 
macuxi e Ingarikó, este último localizados no entorno do Parna Monte Roraima.

Com relação as áreas de potencial parageodiversidade, no entorno da sede do município, este estudo considerou 04 (quatro) áreas com potencial, as quais são ambientes hidrográficos no quais destacam-se: Cachoeira do Paiuá 1, Cachoeira do Paiuá 2, Cachoeira do Urucá, Cachoeira do Urucazinho e Cachoeira Sete quedas (Figura 03).

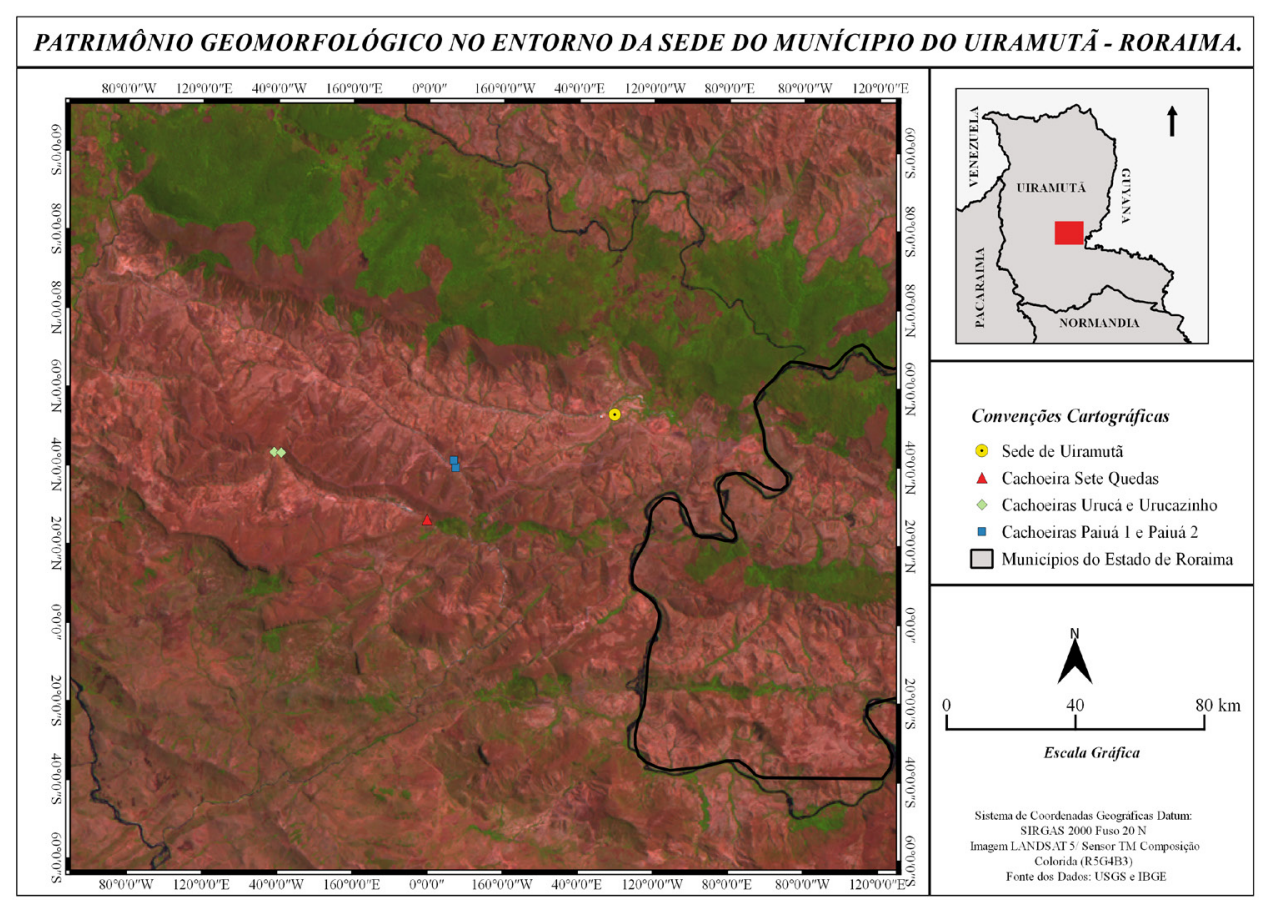

Figura 03. Mapa do patrimônio geomorfológico no entorno da sede do Uiramutã. sadas pelos frequentaFonte: Autores, 2018. dores) e depredação do ambiente geológico.
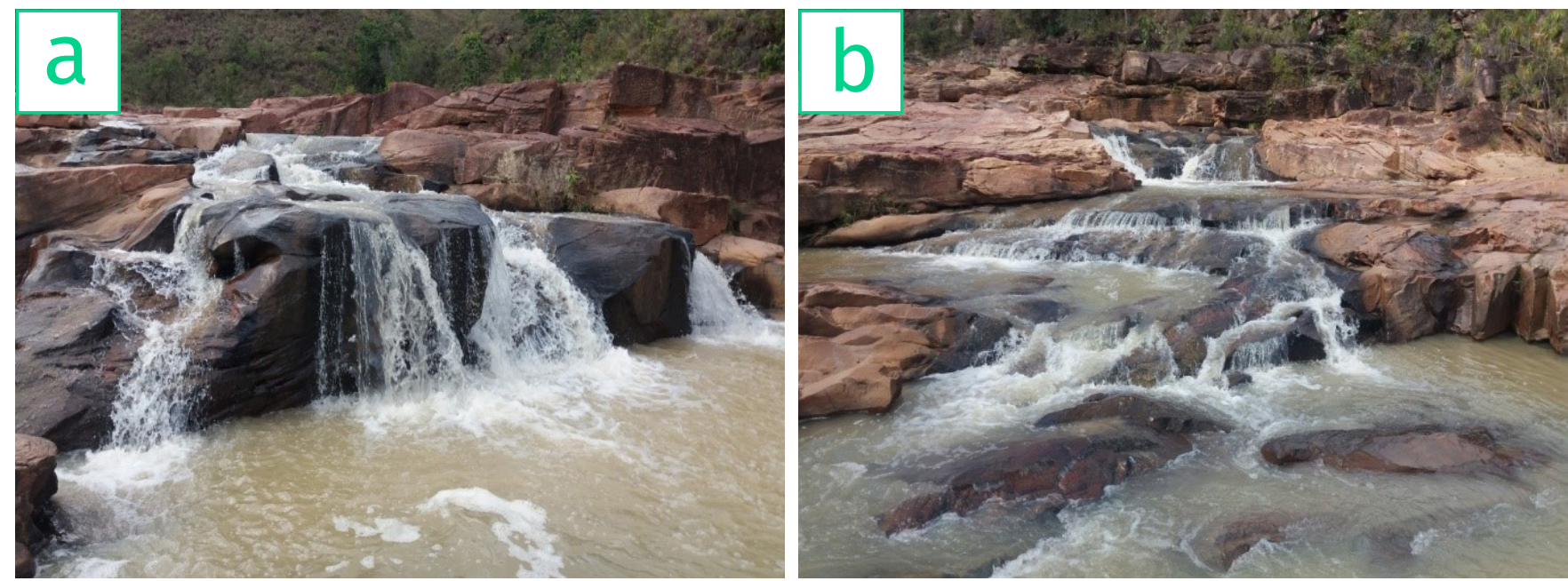

Figura 04. Cachoeira Paiuá1; b) Cachoeira do Paiuá 2. Fonte: Autores, 2017. 


\section{b) Cachoeira Sete Quedas}

Localizada a $11 \mathrm{~km}$ da sede do Uiramu-

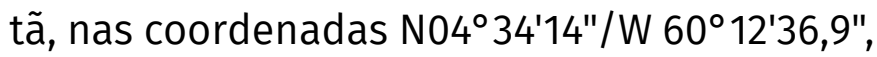
pertence ao igarapé Urucá, trata-se de uma queda d'água com diversos degraus. A geologia é marcada pela presença de arenitos silificados, pertencentes ao Supergupo Roraima (Figura 3).

Conforme o método aplicado o valor para a acessibilidade é baixo por possuir uma trilha muito ingrime com caminhada de 30 minutos. Possui um valor cientifico, estético, ecológico e consequentemente turístico muito elevado, devido a sua singularidade paisagística.

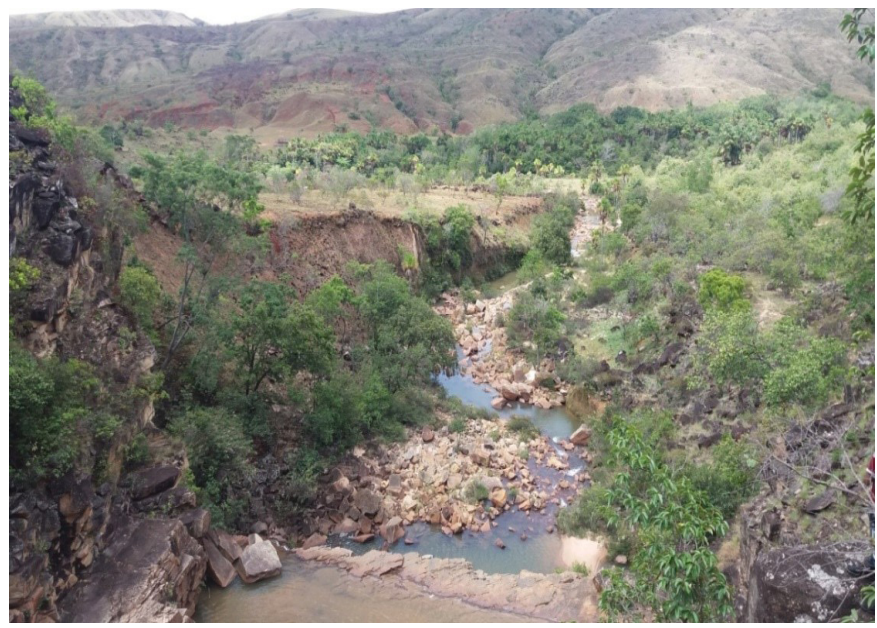

Figura 05. Cachoeira Sete Quedas.

Fonte: Autores, 2017.

\section{c) Cachoeira do Urucá e Urucazinho}

Localizada a $12 \mathrm{~km}$ da sede do município e a $04 \mathrm{~km}$ da Cachoeira Sete Quedas,nas coordenadas N04 $35^{\circ} 09,2^{\prime \prime} / \mathrm{W} 60^{\circ} 14^{\prime} 48.4^{\prime \prime}$; N04 $05^{\prime} 8,3^{\prime \prime} / \mathrm{W} 60^{\circ} 14^{\prime} 42,1$, se localiza no igarapé do mesmo nome (Urucá). Se caracteriza pela presença de uma trilha ingrimeque possui cerca de $300 \mathrm{~m}$ de extensão. Possui uma única queda vertica, formando uma piscina natural com água verde clara. Assim como as outras cachoeiras pertence ao Supergrupo Roraima, e apresenta arenitos silificados com a presença de conglomerados (Figura 06).
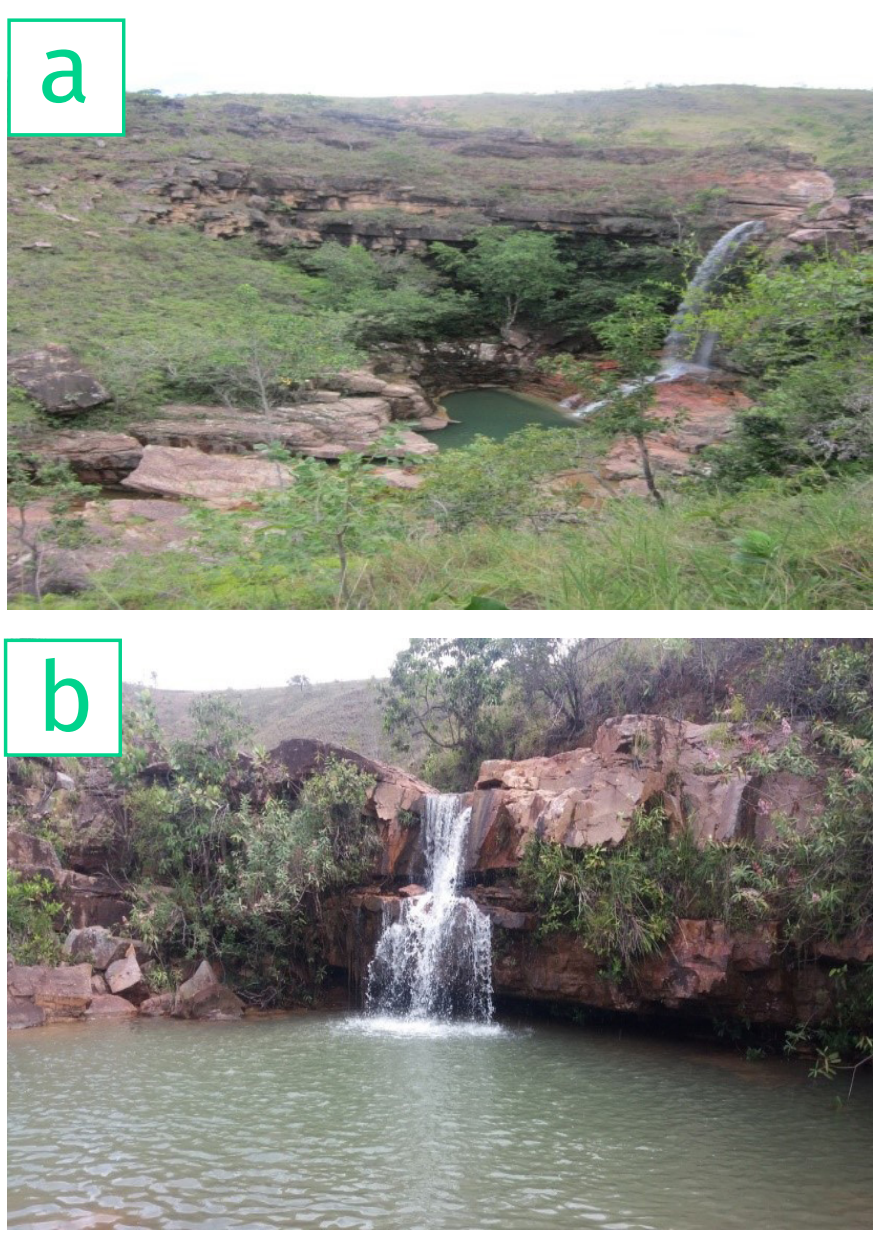

Figura 06. a) Cachoeira do Urucá; b) Cachoeira do Urucazinho.

Fonte: Autores, 2017.

O seu valor científico é elevado, decorrente dos minerais presentes na região. Os seus valores turísticos e estéticos são elevados devido a formação paisagística atraente do local.

Bento (2011, p. 163) comenta que o geoturismo:

[...] novo segmento turístico é tão relevante na atualidade que já existem diversos trabalhos voltados a inventariação da geodiversidade com fins geoturísticos, pois se sabe que o mesmo abarca também aspectos educativos que são de suma importância para mudar a percepção pública referente aos elementos abióticos da natureza.

\section{(1)

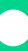

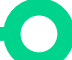




\section{ÁREAS DE INTERESSE GEOMORFO- LÓGICO NA REGIÃO}

O município de Uiramutã possui caracteristicas cênicas devido a ação da natureza, que proporcionam paisagem diferenciada a região, e por consequência uma geodiversidade local diferenciada.

$\mathrm{Na}$ área estudada altitude varia entre 800 e 1000 m de altitude, aliada a uma vegetação de campos rupestres e savanas a região potencializam a região intensos processos erosivos. A região possui restrição agrícola devido a presença de pedregosidade, associada a solos ácidos, rasos e de baixa fertilidade. Ressalta-se ainda a intensidade do desmatamento e das queimadas, em geral decorrentes da cultura dos povos indígenas.

Com relação ao relevo, durante as entrevistas, com os Ingarikó, os mesmos associaram a existência de serras sagradas, que possuem significado místico efazem parte da cultura imaterial desse povoe as não sagradas que são definidas como locais que podem ser utilizados para as atividades do cotidiano (valor funcional), como a implantação de roças na vertente do relevo ou para outros usos, como a captação de água (Quadro 02).

\begin{tabular}{|l|l|l|}
\hline \multicolumn{1}{|c|}{ RELEVO } & \multicolumn{1}{|c|}{ Valor } & $\begin{array}{l}\text { SIGNIFICADO/ } \\
\text { USO PARA OS } \\
\text { INGARIKÓ }\end{array}$ \\
\hline MarîkWîpî & $\begin{array}{l}\text { Funcional e eco- } \\
\text { nômico. }\end{array}$ & $\begin{array}{l}\text { Captação de } \\
\text { água por gravi- } \\
\text { dade para a co- } \\
\text { munidade Serra } \\
\text { do Sol. O conhe- } \\
\text { cimento sobre a } \\
\text { serra foi perdi- } \\
\text { do. }\end{array}$ \\
\hline Monte Roraima & $\begin{array}{l}\text { Intrínseco, cien- } \\
\text { tífico e educa- } \\
\text { tivo, estético e e } \\
\text { econômico. }\end{array}$ & $\begin{array}{l}\text { Sagrado - mo- } \\
\text { rada de Macu- } \\
\text { naima, caixa } \\
\text { d'água. }\end{array}$ \\
\hline
\end{tabular}

\begin{tabular}{|l|l|l|}
\hline $\begin{array}{l}\text { Wîtîpî (Serra do } \\
\text { Sol) }\end{array}$ & $\begin{array}{l}\text { Cultural, intrín- } \\
\text { seco, científico e } \\
\text { educativo. }\end{array}$ & $\begin{array}{l}\text { Sagrado - local } \\
\text { onde estão os } \\
\text { ossos dos ante- } \\
\text { passados. Local } \\
\text { onde o sol foi } \\
\text { preso por cau- } \\
\text { sa da queimada } \\
\text { da floresta e dos } \\
\text { animais. }\end{array}$ \\
\hline Wokmik & Funcional. & Local de caça \\
\hline Aikatêpî & $\begin{array}{l}\text { Cultural e intrín- } \\
\text { seco. }\end{array}$ & $\begin{array}{l}\text { Sagrado -mora- } \\
\text { da de um gran- } \\
\text { de pássaro }\end{array}$ \\
\hline $\begin{array}{l}\text { OknikMururipê } \\
\text { (Monte Caburaí) }\end{array}$ & $\begin{array}{l}\text { Cultural, intrín- } \\
\text { seco, científico e } \\
\text { educativo. }\end{array}$ & Sagrado \\
\hline
\end{tabular}

Quadro 02. Relação relevo, significado para os ingarikó e valor da Geodiversidade. Fonte: Falcão, 2016.

Os ingarikó possuem uma relação mística com o Monte Roraima, pois para eles trata-se da morada de Macunaima, e de onde vem toda a água do planeta. A área circunvizinha é o reduto da busca por alimentos, onde os indígenas caçam e pescam e também cultivam as suas roças. Acreditam na existência de um dragão que vive em dos igarapé da região e que um morcego que mora no topo da Serra do Sol. Relatam que no sopé da mesma serra, encontram-se os restos mortais deseus antepassados e por esse motivo evitam passar próximo desses locais, por considerá-los sagrados.

No entanto, relatam que os turistas que entram pela Venezuela com quadriciclos adentram esses locais sagardos, violam as urnas dos antepassados além de destruírem esse patrimônio cultural.

Durante as incursões em campo, foi solicitado aos entrevistados que produzissem um mapa cognitivo de interesse turístico, visto que todos relatam a importância da paisagem cênica da região (Figura 07). 


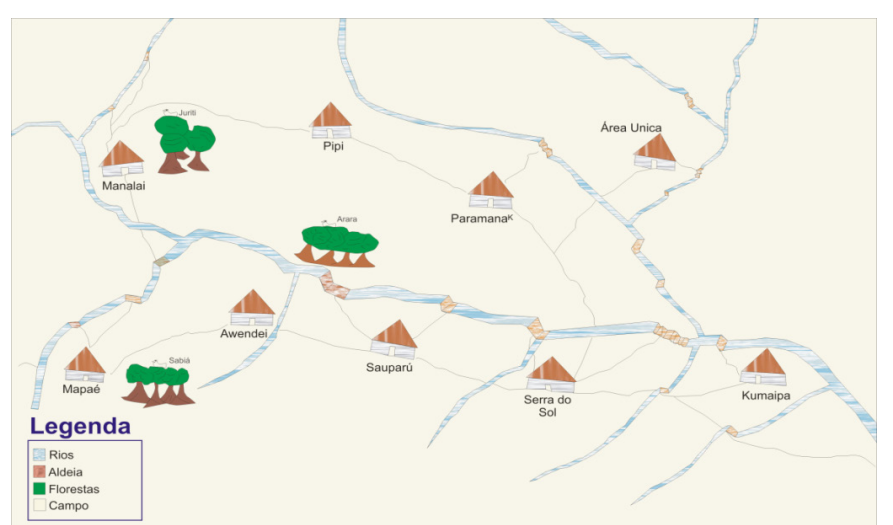

Figura 07. Mapa cognitivo Ingarikó-Comunidade Mapaé. Fonte: Falcão, 2016.

No mapa cognitivo, os entrevistados destacaram as vias de acesso entre as comunidades que, na visão deles, possuem potencial significativo para o desenvolvimento turístico tais como: observação de pássaros, rede de drenagem com trechos de corredeiras e cachoeiras onde poderia se realizar rafting, bem como caminhadas nas trilhas entre as comunidades.

Para Falcão (2016) atualmente os Ingarikó discutem em suas assembleias a introdução do etnoturismo como alternativa econômica para a região, cabe ressaltar que o turismo em terra indígenas ( $\mathrm{TI}$ ) não era regulamentado até junho de2015, quando entrou em vigor a Instrução Normativa 03/2015, da Funai, a qualregulamenta e estabelece normas para a visitação em TI para fins turísticos.

A regulamentação 03/2015 é um dos desdobramentos da Política Nacional de Gestão Territorial e Ambiental em Terras Indígenas (PNGATI) que prevê "apoiar iniciativas indígenas sustentáveis de etnoturismo e de ecoturismo, respeitada a decisão da comunidade e a diversidade dos povos indígenas, promovendo-se, quando couber, estudos prévios, diagnósticos de impactos socioambientais e a capacitação das comunidades indígenas para a gestão dessas atividades" (BRASIL, 2012).

A Funai proibiu a realização por agências de turismo de Roraima de realizar passeios nas cachoeiras que ficam dentro da Terra Indígena Raposa Serra do Sol, no município de
Uiramutã, a cerca de 300 quilômetros de Boa Vista. Essa questão se deu devido as diversas reclamações de indígenas.

Nogueira (2013), destaca que inserção do turismo em comunidades indígenas deve ser cuidadosa, para evitar distúrbios sociais e invasão à privacidade dos moradores. É importante lembrar que algumas festas e cerimônias devem ser resguardadas, quando assim a comunidade desejar, a fim de manter as tradições vivas e autênticas. Também é fundamental que as atividades de turismo étnico sejam praticadas por turistas que tragam consigo o interesse autêntico pela natureza e cultura do local a ser visitado (FALCÃO; NOGUEIRA; SANTOS, 2014).

\section{CONCLUSÃO}

O município do Uiramutã possui ricos elementos da geodiversidade, sendo os valores principais o científico, estético e turístico. O valor cientifico se traduz na riqueza e variação dos minerais, das rochas e do solo que são encontrados ao longo na sede do município. 0 valor estético é devido a sua beleza natural e paisagística, como as serras, corredeiras e cachoeiras que são presentes no local. E o valor turístico que se configura a partir dos dois anteriores, pois possui um grande potencial para a atividade turística na região.

No entanto, é importante ressaltar que o desenvolvimento da atividade turística para região, requer autorização dos povos que alí vivem, e que estes sejam capacitados para serem protagonistas de tal atividade.

Por fim, é importante ressaltar que o turismo (etnoturismo) nas terras indígenas, deve contribuir paraa divulgação da identidade do povo, bem como trazer melhorias socioeconômicas. A região estudada, apresenta limitações agrícolas, pois o solo é bastante ácido, dificultando a produção. Dessa forma, a paisagem, em especial geomorfológica, apresenta-se como um cenário quase único na região Amazônica, além da cultura e da gas- 
tronomia do povo Ingarikó, poderá contribuir para a sustentabilidade econômica e o protagonismo local.

\section{AGRADECIMENTOS}

Ao povo ingarikó pela permissão para o desenvolvimento da pesquisa. Ao CNPq através da concessão de Bolsa de Iniciação Científica - PIBIC, para a segunda autora, referente ao desenvolvimento da pesquisa no entorno da sede do município do Uiramutã.

\section{REFERÊNCIAS}

BENTO, L. C. M. Um novo olhar para a geodiversidade através do geoturismo. Enciclopédia Biosfera, Centro Científico Conhecer - Goiânia, vol.7, N.12; 2011. p. 159-165.

BRASIL. Decreto no 7.747, de 5 de junho de 2012. Institui a Política Nacional de Gestão Territorial e Ambiental de Terras Indígenas - PNGATI. Diário Oficial da União, Brasília, DF,6 jun. 2012. Seção 1. Disponível em: <http:/ / www.planalto. gov.br/ccivil_03/_ato2011-2014/2012/decreto/ d7747htm>. Acesso em: 09 jul. 2018.

BRILHA, J. Patrimônio Geológico e Geoconservação: A Conservação da Naturezana sua Vertente Geológica. Braga: Palimage Editores, 2005.

FALCÃO, M.T; COSTA, J. A. V. Paisagem geomorfológica da Terra Indígena Raposa Serra do Sol Uiramutã/Roraima/Brasil. Revista Geonorte, v. 10, p. 71-75, 2012. Disponivel em: < http:/ / www.revistageonorte.ufam.edu.br/attachments/009_(GEOMORFOLOGIA\%20DA\%20 REGI\%C3\%830\%20CENTRO-NORTE\%20DE\%20 RORAIMA\%20\%20UTILIZANDO\%20T\%C3\%89CNICAS\%20DE\%20TRATAMENTO\%20E\%20INTERPRETA\%C3\%87\%C3\%830\%20DE\%20IMAGENS\%20).pdf >. Acesso em: 20 jan. 2017.

FALCÃO, M.T. Ambiente e conhecimento tradi- cional da etnia Ingarikó na terra indígena Raposa Serra do Sol - Roraima: abordagem etnocientífica no estudo do uso da terra. 2016. 105f. Tese. (Doutorado em Biodiversidade e Conservação) - Museu Paraense Emilio Goeldi Belém - PA, 2016.

FALCÃO, M.T.; NOGUEIRA, E.M.; SANTOS, R.M.R. Etnoturismo, experiências e perspectivas vivenciadas com os Ingarikó na Terra Indígena Raposa Serra do Sol - Roraima/Brasil. In: LIMA, I.B. (Org.). Etnodesenvolvimento e gestão territorial: comunidades indígenas e quilombolas. Curitiba: Editora CRV, 2014. p. 107-121.

FERNANDES-PINTO, E; IRVING, M.A. Valores culturais e espirituais do Parque Nacional doMonte Roraima/RR: um horizonte inexplorado. 4 CONGRESSO INTERNACIONAL INTERDISCIPLINAR EM SOCIAIS E HUMANIDADES. Anais... Paraná, 2015. Disponível: <http://www.aninter.com.br/Anais\%20Coninter\%204/GT\%20 09/01.\%20VALORES\%20CULTURAIS\%20E\%20 ESPIRITUAIS\%20DO\%20PARQUE\%20NACIONAL\%20DO\%20MONTE\%20RORAIMA\%20-\%20 01-22.pdf>. Acesso em: 02 ago 2017.

FUNAI. Instrução Normativa no 3, de 11 de junho de 2015. Estabelece normas e diretrizesrelativas às atividades de visitação para fins turísticos em terras indígenas. DiárioOficial da União, Brasília, DF, 12 jun. 2015b. Seção 1, n. 110, p. 41-43. Disponivel em:<http://pesquisa.in.gov.br/imprensa/jsp/visualiza/index. jsp?jornal=1\&pagina=41\& - data $=12 / 06 / 2015>$. Acesso em: 4 ago. 2017

FUNAI. proíbe agências de turismo de realizar passeiosem cachoeiras. Folha de Boa Vista, Boa Vista, 14 mar. 2017. Cidades, p. 3.

GARCIA, T.S. Da geodiversidade ao geoturismo:valorização e divulgação do geopatrimôniode Caçapava do Sul, RS, Brasil. 2014. 180f. Dissertação. (Mestrado em Geografia). Santa Maria, RS, 2014. Disponível em: <http://w3.ufsm.br/ 
ppggeo/images/dissertacoes/dissertacoes_2014/Ta\%C3\%ADs\%20da\%20Silva\%20Garcia_Disserta\%C3\%A7\%C3\%A30\%20de\%20Mestrado.pdf>. Acesso em 22 set. 2017.

IRVING, M. Reinventando a reflexão sobre turismo de base comunitária: inovar é possível? In: Turismo de Base Comunitária: diversidade de olhares e experiências brasileiras. Orgs. Roberto Bartholo, Davis Gruber Sansolo, Ivan Bursztyn. Rio de Janeiro: Letra e Imagem, 2009.

MOREIRA, J. C. Geoturismo: uma abordagemhistórico-conceitual. Revista Pesquisas em Turismo e Paisagens Cársticas, Campinas-SP, v. 3, n. 1, p.5-10, 2010.

NASCIMENTO, A.L.; RUCHKYS, U.; MANTESSO-NETO, V. Geodiversidade, geoconservação e geoturismo: trinômio importante para a proteção do patrimônio geológico. SBG, 2008.

NOGUEIRA, E. Etnodesenvolvimento e educação indígena: problemas e perspectivas para a implantação do etnoturismo na terra indígena raposa serra do sol (TIRSS), região ingarikó wîitîpî. Dissertação de mestrado em Educação Agrícola, no Programa de Pós-Graduação em Educação Agrícola, Área de Concentração em Educação Agrícola. Seropédica, RJ. Junho de 2013.

OLIVEIRA, P. C. A. Avaliação do patrimônio geomorfológico dos municípios de Coromandel e Vazante, M.G.2015. 176f. Tese. (Doutorado em Geografia) - Universidade Federal de Uberlândia. Uberlândia - MG, 2015.

SILVA, R. D. M.; CRUZ, J.; PY-DANIEL, V. Monte Roraima na América do Sul, Venezuela: DestinoMundial do Turismo de Natureza. Revista de Turismo y Patrimonio Cultural, vol. 9, n.2, 2011. p.411-422. Disponivel em: <http://www. pasosonline.org/Publicados/9211/PS0211_15. pdf>. Acesso em: 11 jan. 2018. 